\title{
A Ciência de Freud: introdução ao problema da CIENTIFICIDADE DA PSICANÁLISE ${ }^{\star}$
}

\author{
Nathalia Sisson $\star \star$

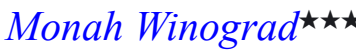

\begin{abstract}
Resumo
Apresenta-se primeiramente a concepção de Freud do que seria a Ciência e em que constituiria a atividade cientifica, utilizando-se textos freudianos nos quais ele trabalha esse tema. Considera-se as noções de Naturwissenchaft $e$ Geistwissenchaft para contextualizar a discussão sobre a cientificidade da Psicanálise à época de Freud. Confronta-se então a Ciência, como entendida por Freud, com as concepções de Popper e Bachelard, oriundos da Epistemologia. Posteriormente, apresentamos diferentes posições de psicanalistas, como Lacan e Kernberg, quanto ao mesmo tema, para mostrar como a compreensão do que seja a Ciência determina os posicionamentos quanto à relação entre esta e a Psicanálise.
\end{abstract}

Palavras-chave: psicanálise; ciência; epistemologia; pesquisa cientifica-psicanálise.

\section{FreUd's SCIENCE: AN INTRODUCTION TO THE ISSUE OF PSYCHOANALISIS' SCIENTIFIC STATUS}

\begin{abstract}
The article presents Freud's conception of Science and the scientific enterprise using Freudian texts in which the author writes specifically about the scientific issue regarding psychoanalysis. To broaden the discussion, the german notions of Naturwissenchaft and Geistwissenchaft are introduced so as to shed light on the notions from which and with which Freud was dealing with. After this contextualization, Freud's conception of science is confronted with the conceptions of Popper and Bachelard regarding science, as well as with other psychoanalysts ideas on this matter, such as Lacan and Kernberg, showing how their way of understanding science determines their position on the matter of Science and Psychoanalysis.
\end{abstract}

Keywords: psychoanalysis; science; epistemology; scientific research-psychoanalysis

^Este artigo foi produzido como parte das atividades de pesquisa previstas no âmbito do projeto 401750/07-8 (CNPq/ Edital Ciências Humanas e Sociais).

$\star \star$ Psicóloga, Mestranda em Psicologia Clínica pela Pontifícia Universidade Católica do Rio de Janeiro, Bolsista do CNPQ.

E-mail: nathalia.sisson@gmail.com

$\star \star \star$ Psicanalista, Professora Assistende do Progrma de Pós-graduação em Psicologia Clínica/ Pontifícia Universidade Católica do Rio de Janeiro, coordenadora do grupo de pesquisa MateriaPensante. Endereço: Departamento de Psicologia - Rua Marquês de São Vicente, 225 - CEP:22453-900 Gávea - Rio de Janeiro - RJ.

E-mail:winograd@uol.com.br 
Nos últimos anos, assistimos a atualização do debate sobre a cientificidade da psicanálise devido, em boa parte, ao desenvolvimento e à expansão das Neurociências em direção a fenômenos que, até então, haviam sido explorados quase que exclusivamente pela psicanálise. As conexões possíveis entre psicanálise e Neurociências têm sido objeto de diversos estudos tanto sobre como situar as contribuições de um campo de saber ao outro (FAVERET, 2006; KAPLANSOLMS; SOLMS, 2005) quanto sobre como as Neurociências poderiam fornecer comprovação científica para os conceitos psicanalíticos (ADREASEN, 2005 apud GRAEFF, 2006, p. 31). Vê-se como este debate teve o potencial de reativar, mais uma vez, a questão da (a)cientificidade da psicanálise, dando origem aos mais variados posicionamentos e argumentações e envolvendo desde filósofos a cientistas e psicanalistas.

Há quem considere ser a psicanálise, sim, uma ciência (LO BIANCO, 2003; MEZAN, 2007; ROLIM, 2000; PRUDENTE; RIBEIRO, 2005), enquanto outros afirmam que ela deveria passar por revisões profundas para se encaixar no perfil de uma produção científica (KERNBERG, 2006; WALLERSTEIN 1986; CLARKIN et al., 1999). Há, ainda, quem entenda que, não só a psicanálise não é ciência, como não interessa à primeira incluir-se na segunda, pois se tratam de dois campos de saber radicalmente diferentes e irredutíveis um ao outro (LACAN, 1985[1964], 1988[1965]; MILLER, 2002). Para investigar esta questão, utilizaremos como ponto de referência inicial os argumentos do próprio Freud, cuja posição em relação à indagação de se a psicanálise poderia ou não ser considerada uma ciência manteve-se consistente ao longo de toda a vida.

Desde cedo, Freud esteve em contato estreito com a atividade científica, já que sua educação formal de médico e pesquisador se deu em meio às pesquisas acadêmico-científicas do fim do século XIX. Sua formação continuou no Laboratório de Fisiologia da Universidade de Viena, onde desenvolveu pesquisas experimentalmente controladas, o que certamente fez com que ganhasse bastante intimidade com os procedimentos investigativos da produção científica de sua época (PRUDENTE; RIBEIRO, 2005). Ainda que sua produção posterior tenha se dado fora da academia, Freud nunca duvidou de que fazia ciência, como escreve logo no início do Projeto de 1895: "a finalidade deste projeto é estruturar uma psicologia que seja uma ciência natural [...]" (FREUD, 1996[1895], p. 395). Em vários momentos de sua obra ele reafirma essa intenção, por exemplo, ao comparar a psicanálise com a Filosofia, defendendo-a da medicina (FREUD, 1996[1925]), ao discorrer sobre o pensamento e a prática científica (FREUD, 2004[1914], 2004[1915], 1996b[1933]) ou ao analisar o método psicanalítico (FREUD, 1996[1940]). Nestas ocasiões, o metapsicológo revela uma concepção clara sobre a produção de saber na ciência, articulando-a de maneira coerente a sua metodologia de investigação dos processos psíquicos, cujo valor considerava inestimável (FREUD, 1996[1940]) - para ele, a prova de cientificidade da psicanálise era justamente sua metodologia de investigação.

Freud sempre entendeu a psicanálise não só como uma ciência, mas como uma Ciência da Natureza, uma Naturwissenchaft, (FREUD, 1996b[1933]) tal como a Física, a Química ou a Fisiologia, e não como uma Geisteswissenschaft, uma 
Ciência do Espírito. São diversos os testemunhos claros desse modo de pensar: o início do artigo "Pulsões e destinos de pulsão" (FREUD, 2004[1915]), sua Autobiografia (FREUD, 1996[1925]), o artigo "À guisa de introdução ao narcisismo" (FREUD, 2004[1914]), o texto "A questão de uma Weltanschauung" (FREUD, 1996b[1933]) e também o "Esboço de psicanálise" (FREUD, 1996[1940]) são os mais significativos a respeito desse tema.

A respeito da firme convicção de Freud sobre a pertença da psicanálise às Ciências da Natureza, Assoun (1983, p. 53, grifo do autor) escreve: "Para Freud, a psicanálise não constitui um intermediário na encruzilhada das duas esferas: ela se encontra inteiramente, por essência, e tende a estar, por vocação, do lado da esfera da natureza". Ora, o que mais a psicanálise poderia ser, senão uma Naturwissenschaft? Para que possamos compreender esta pergunta formulada por Freud (1996[1940]), é preciso que retornemos ao contexto alemão de sua época para apreender os tipos de ciência em vigor em seu ambiente cultural e científico. Ao final deste movimento, veremos revelarem-se as opções de respostas à disposição de Freud e o sentido da categorização da psicanálise como Ciência da Natureza.

\section{A Querela dos Métodos (Methodenstreit)}

O debate que teve lugar na Alemanha no final do século XIX e inicio do século XX ficou conhecido como "A querela dos métodos", ou seja, o período no qual a psicanálise era inventada foi também o momento de uma transformação no campo da epistemologia, provocada pelo surgimento das Ciências do Espírito e, conseqüentemente, da disputa entre a Naturwissenschaft e as Geisteswissenschaften. Segundo Assoun (1983, p. 45), a questão central jazia nas condições de possibilidade do conhecimento e se fundava "[...] numa separação entre as esferas da natureza, susceptível aos métodos que já haviam sido comprovados na ciência clássica (galileana), e uma esfera da história e do homem, que precisava dotar-se de uma metodologia sui generis". Considerava-se haver basicamente dois tipos de objeto para o saber: os naturais e os históricos ou culturais. Os primeiros eram considerados como independentes da participação humana, tanto em sua existência como em seu modus operandi. Por sua vez, os segundos referiam-se a tudo o que resultasse da vida em sociedade e caracterizasse a existência humana. Entre um e outro, entre o "humano" e o "natural", haveria uma diferença ontológica que exigia o emprego de métodos diversos em seu estudo (MEZAN, 2007). Assim, o método das Naturwissenchaft baseava-se na explicação (erklären), enquanto as Geisteswissenschaften tinham como fundamento a interpretação e a compreensão (verstehen). Se a primeira tinha como meta a explicação dos fenômenos através do modelo investigativo da Física de Galileu e Newton, as segundas, por sua vez, buscavam compreender os acontecimentos através da hermenêutica. A sistematização das diferenças entre os dois tipos de ciência foi realizada por Wilhelm Dilthey (1949[1883]) em seu célebre livro Introdução às Ciências do Espírito.

Nas Ciências da Natureza, o individuo ou grupo de indivíduos era tomado como exemplo de toda sua categoria por possuir a capacidade de englobar em si toda a classe de seres à qual pertence, ou seja, encontra-se inteiramente identifi- 
cado com a totalidade de sua espécie. De modo que era preciso apreender o que haveria de universal no espécime e não o que ele poderia apresentar como singular ou individual. Ora, para que essa exploração fosse possível, a Natureza precisava ser entendida como dotada de constância confiável para dar a garantia de que o experimento repetido fosse igual ao anterior. Daí estas ciências terem utilizado procedimentos essencialmente indutivos e formulado leis das quais é possível deduzir outras propriedades ou comportamentos passíveis de serem verificados por observações e experimentos. Deste movimento entre as observações e a teorização se pode formular hipóteses com a capacidade de explicar os fatos: extrai-se o universal do particular, pois o segundo é mero exemplo do primeiro (ASSOUN, 1983)

Tudo muda nas Ciências do Espírito, pois, a investigação sobre o domínio propriamente humano revela a inadequação dos procedimentos das Ciências da Natureza: cada objeto apresenta individualidade própria irredutível a uma classe no sentido atribuído ao termo pela Ciência da Natureza (MEZAN, 2007). Para dar conta da singularidade de um individuo ou grupo, como as civilizações, as obras de arte, os sistemas políticos e econômicos etc., parecia ser necessário interpretá-los para compreendê-los (verstehen), ou seja, penetrar em seu sentido, "[...] transcrever o individual sem dissolvê-lo em qualquer mediação conceitual" (ASSOUN, 1983, p. 47). E o método para realizar tal empreendimento era a hermenêutica, a qual permitiria a compreensão profunda dos fenômenos ao invés de sua explicação. Operando pela interpretação das realidades que investigava, tal método permitira esclarecer suas significações e os meios através dos quais elas se expressavam, sua articulação interna, suas relações com outras facetas de um sistema cultural e as diferenças em relação a equivalentes em outros sistemas culturais (MEZAN, 2007). Contudo, se a Naturwissenschaft atinha-se aos juízos de realidade, as Geisteswissenschaften acabavam recorrendo à valorização (ASSOUN, 1983): as interpretações das Ciências do Espírito apresentavam inevitavelmente juízos de valor que expressavam a infiltração de preconceitos ideológicos em suas análises e refletiam o eurocentrismo da época, chegando mesmo a revelarem a xenofobia de nações em relação a outras (MEZAN, 2007).

Paul-Laurent Assoun (1983) argumenta que Freud defendia ser a psicanálise uma Ciência da Natureza por estar inscrito em uma tradição cientifica que não admitia a possibilidade de se fazer outro tipo de ciência que não Ciência da Natureza: Freud "[...] não conhece outra forma de ciência" (ASSOUN, 1983, p. 48). Para o metapsicólogo, a cientificidade só poderia advir da adoção das normas e dos procedimentos propostos pela Ciência da Natureza, os quais garantiriam a reflexão neutra e racional sobre os dados coletados durante a observação atenta e cuidadosa, tendo em vista uma maior precisão dos conceitos. Ora, o método proposto pelas Ciências do Espírito tinham, não a observação, mas valores $a$ priori como base do conhecimento, o que anularia toda e qualquer possibilidade de exercício da racionalidade cientifica. Daí Freud conceber a atividade do cientista/psicanalista como um árduo trabalho de obtenção de dados e lapidação dos conceitos através da colaboração contínua e constante entre a observação e a teorização, seguindo os procedimentos da Ciência da Natureza. 


\section{Freud e a Ciência}

Freud apresenta brevemente sua concepção de como a ciência funciona tanto em "À Guisa de Introdução ao Narcisismo" (FREUD, 2004[1914]), quanto no primeiro parágrafo de "Pulsões e destinos da pulsão" (FREUD, 2004[1915]). No primeiro texto, ele escreve, que mesmo quando as ciências operam com conceitos básicos e claramente definidos, tais conceitos corresponderiam, na realidade, ao topo do edifício, produzido ao final de todo um processo de construção e desenvolvimento do trabalho. Mesmo assim, é imprescindível à ciência que tais definições não sejam rígidas e possam ser removidas e substituídas na medida em que o conhecimento avance e modificações sejam necessárias (FREUD, 2004[1914]).

Quanto ao começo desse processo, ele nos diz que:

[...] o verdadeiro início da atividade científica consiste na descrição de fenômenos que são em seguida agrupados, ordenados, e correlacionados entre si. Além disso, "é inevitável que, já ao descrever o material, apliquemos sobre ele algumas idéias abstratas obtidas não só a partir de novas experiências, mas também oriundas de outras fontes." Tais idéias iniciais - os futuros conceitos básicos da ciência - se tornam ainda mais indispensáveis quando mais tarde se trabalha sobre os dados observados. No princípio, as idéias devem conter certo grau de indefinição, e ainda não é possível pensar em uma delimitação clara de seu conteúdo. Enquanto elas permanecem nesse estado, podemos concordar sobre seu significado remetendo-nos repetidamente ao material experiência a partir do qual elas aparentemente foram derivadas; contudo, na realidade, esse material já estava subordinado a elas. Em rigor, essas idéias possuem o caráter de convenções. Entretanto, é preciso que não tenham sido escolhidas arbitrariamente, e sim determinadas pelas relações significativas que mantém com o material empírico (FREUD, 2004[1915], p. 145, grifo nosso).

Ou seja, há uma etapa anterior à observação e à experimentação, na qual participam idéias abstratas que têm sua origem nas mais variadas fontes. São essas idéias que, mesmo sem uma delimitação ou definição clara, guiarão as observações, as descrições dos fenômenos e as conclusões posteriores, por mais que pareça que estas últimas surgiram do material advindo da experiência. Logo, nenhuma observação pode ser pura, dependendo sempre de alguma referência que permita a interpretação e o trabalho sobre o material empírico e mesmo a coleta desse material. Neste modo de pensar, a pesquisa é o instrumento principal e é entendida como "[...] a elaboração intelectual de observações cuidadosamente escolhidas" (FREUD, 1996 b [1933], p. 156).

Mas, para Freud, este modo de proceder não difere e nem diverge do pensamento normal, apenas desenvolve características específicas, quais sejam: (1) o interesse por determinadas coisas e a evitação cuidadosa de fatores individuais e 
influências afetivas; (2) o exame rigoroso da credibilidade dos sensos de percepção nos quais baseia suas conclusões; (3) a capacidade de se equipar com novas percepções que não seriam de obtenção possível por meios habituais e (4) o isolamento de fatores determinantes dessas novas experiências em experimentações modificadas deliberadamente (FREUD, 1996b[1933]). Além disso, o objetivo do trabalho científico é o de chegar à correspondência com a realidade externa, fora de nós, independente de nós, mas da qual necessitamos para a satisfação de desejos e necessidades. Essa correspondência seria o critério de verdade científico e, para Freud (1996b [1933]), as "normas da vida" seriam, no final, a aplicação de tais verdades alcançadas pela pesquisa. Somente através desse procedimento poder-se-ia construir um conhecimento acerca do universo, já que para ele a ciência exigiria a separação das ilusões e dos aspectos emocionais, não podendo contar com outras fontes de conhecimento, como a intuição, a revelação ou a adivinhação. À ciência caberia o papel de crítica constante, apresentando sempre objeções e refutações e sustentando o ceticismo frente aos conteúdos que surgem, o que permitiria que ela permanecesse em mudança e atualização incessantes, resultando no aperfeiçoamento de seus fundamentos.

Vê-se que a idéia de ciência e do modo através do qual ela é capaz de produzir um conhecimento do mundo está, para Freud, estreitamente vinculada ao desenvolvimento de pesquisa, à metodologia própria de cada ciência e às técnicas de que elas dispõem para alcançar uma correspondência com a realidade exterior, recorrendo sempre à observação. É exatamente sobre esses termos que Freud (2004[1914]; 1996[1940]) fundamenta seus argumentos sobre a cientificidade da psicanálise, pois para ele, a vida psíquica apresenta-se como objeto de pesquisa possível da mesma forma que um objeto externo. A grande contribuição da psicanálise seria, então, a de "[...] ter estendido à área mental as pesquisas cientificas" (FREUD 1996b[1933], p. 156), o que fez com que ela pudesse constituir-se como ciência, não só dos processos psíquicos conscientes, como também dos inconscientes.

Para isso, a psicanálise apossou-se da idéia de que haveriam processos psíquicos inconscientes - cuja prova experimental seria possibilitada pela hipnose - e, debruçando-se sobre eles, transformou-os em conceito. Em suas palavras:

Enquanto que a psicologia da consciência nunca foi além das seqüências rompidas que eram obviamente dependentes de algo mais, a outra visão, que sustenta que o psíquico é inconsciente em si mesmo, capacitou a Psicologia a assumir seu lugar entre as ciências naturais como uma ciência. Os processos em que está interessada são, em si próprios tão incognoscíveis quanto aqueles de que tratam as outras ciências, a Química ou a Física, por exemplo; mas é possível estabelecer as leis a que obedecem e seguir suas relações mútuas e interdependentes ininterruptas através de longos trechos - em resumo, chegar ao que é descrito como uma 


\begin{abstract}
A Ciência de Freud: introdução ao problema da cientificidade da psicanálise
'compreensão' do campo dos fenômenos naturais em apreço. Isto não pode ser efetuado sem a estruturação de novas hipóteses e criação de novos conceitos, e estes não devem ser menosprezados como indicio de embaraço de nossa parte, mas, pelo contrário, merecem ser apreciados como um enriquecimento da Ciência. (FREUD, 1996[1940], p. 227).
\end{abstract}

A hipótese psicanalítica do aparelho psíquico, portanto, colocaria a psicanálise em condições de estabelecer bases próximas das outras ciências, na medida em que Freud (2004[1915], p. 145) entende ser fundamental, em todas as ciências, a elaboração de uma idéia inicial que oriente a aproximação do objeto. Além da formulação de hipóteses, Freud (2004[1914]; 2004[1915]) afirma ser importante também a criação de novos conceitos que possibilitarão uma melhor definição do objeto a ser investigado e uma melhor compreensão do fenômeno em questão. A psicanálise trabalha com hipóteses sempre abertas à revisão e, tal como outras pesquisas científicas, busca, para além dos atributos do objeto que se apresentam diretamente às percepções, algo que seria mais independente de nossas capacidades perceptivas e que se aproximaria do que se supõe ser o estado real das coisas. $O$ procedimento da psicanálise para alcançar estes novos conteúdos que auxiliem o entendimento consiste na utilização de:

[...] métodos técnicos de preencher as lacunas existentes nos fenômenos de nossa consciência e fazemos uso desses métodos exatamente como um físico faz uso de sua experiência. Dessa maneira, inferimos certo numero de processos que são em si mesmos 'incognoscíveis' e os interpolamos naqueles que são conscientes para nós (FREUD, 1996[1940], p. 226).

Ou seja, a psicanálise possui métodos técnicos específicos a sua prática que desempenham a mesma função que a experiência na Física.

Embora o próprio Freud (1996[1940]) reconheça que a vida anímica seja um dos mais difíceis objetos de exame científico, as descobertas da psicanálise tornariam possível o preenchimento das lacunas de percepção necessárias à investigação dos processos psíquicos, pois o trabalho da análise consistiria eminentemente em traduzir processos inconscientes em conscientes. Para que essa tradução possa ser realizada, a psicanálise conta com sua técnica, com a formação de conceitos e com a formulação de hipóteses, o que, em suma, lhe conferiria o estatuto de ciência. No entanto, apesar de Freud (1996a[1933]) sempre haver defendido a legitimidade do tratamento psicanalítico e a posição da psicanálise como Ciência da Natureza, muitas foram as resistências contra a novidade que ela trazia ao pensamento científico e intelectual. A discussão acerca da cientificidade da psicanálise tomou diversos rumos ao longo do tempo, todos vinculados a uma concepção de Ciência e do que seria a produção desta. 


\section{O problema da Cientificidade da PSiCAnálise: Popper e BaChelard}

Um dos mais célebres epistemólogos, Karl Popper, não apenas fez questão de explicitar sua opinião pessoal a respeito da teoria de Freud, como deixou claro que seu critério de cientificidade exclui completamente a possibilidade de inclusão da invenção freudiana dentre as ciências (POPPER, 1991). Para Popper (1991), a psicanálise seria um programa metafísico e, enquanto tal, estaria apta a fornecer um ponto de saída para alguma ciência, uma idéia sobre a qual uma ciência poderia se debruçar segundo um método que estivesse de acordo com os critérios de cientificidade de Popper. Porém, ela mesma não poderia constituir-se enquanto uma porque simplesmente não atende aos critérios lógicos estabelecidos como necessários a toda teoria científica, a saber, possuir uma estrutura tal que permita a possibilidade de tal teoria ser provada errada, ou seja, ser "falseável". É essa possibilidade implícita à estrutura lógica de uma teoria científica que possibilitaria o progresso da ciência, pois, no momento em que uma hipótese for falsificada, outra hipótese mais capaz surgirá. Como, a seu ver, a teoria psicanalítica pretende poder explicar todos os acontecimentos do psiquismo humano, ela não pode ser refutada e, conseqüentemente, não é falsificável.

Já outro célebre estudioso das ciências, Bachelard (1991; 2005), pensava que a psicanálise talvez fosse uma das disciplinas mais cientificas. Pois, se a ciência existe a partir de um corte epistemológico, ou seja, se ela se movimenta contra o senso comum e o pensamento não-científico, o conceito freudiano de Inconsciente poderia ser considerado um exemplo perfeitamente adequado de conhecimento científico. Além disso, a ciência ainda deve enfrentar criticamente as oposições e as resistências a ela direcionadas, para que possa romper com o saber já constituído que se apresenta como obstáculo. Inevitável considerar que tais critérios de cientificidade parecem aplicar-se ao processo de constituição da psicanálise em sua totalidade, pois — como é sabido — ela enfrentou inúmeras oposições, resistências e intolerâncias por parte do saber oficial da época em que surgiu (JAPIASSU, 1989; FREUD, 1996[1925]). Como o próprio metapsicólogo reconheceu, o conceito de Inconsciente rompeu com e subverteu a concepção hegemônica da psicologia da consciência, propondo também uma teoria inédita do processo de constituição do psiquismo (FREUD, 1996[1940], p. 227). Ademais, as noções do próprio Freud (2004[1915]) a respeito do pensamento científico se assemelham bastante com as de Bachelard (2005): ambos afirmam ser absolutamente necessário haver contextos, perguntas e idéias prévias que oriente a observação, a qual nunca é pura. Em Freud (2004[1915]), esse argumento está claramente presente no início do artigo Pulsão e vicissitudes da pulsão, onde ele escreve que a própria descrição do material obtido já é influenciada por idéias abstratas, obtidas das mais variadas fontes, e que só posteriormente esses dados podem ser ordenados e agrupados.

Ainda, para Bachelard (2005), o fenômeno a ser delimitado é totalmente dependente da técnica utilizada para seu conhecimento. Ou seja, toda ciência é necessariamente uma tecnociência caracterizada pela fenomenotécnica: o fenômeno, na realidade, só existe se vinculado à tecnologia ou aos procedimentos 
técnicos que possibilitam sua emergência. Por essa razão a experiência científica vai de encontro à experiência comum e a contradiz, baseando-se não no real, mas no artificial, na abstração que permite uma crítica racional do experimento. Nas palavras do epistemólogo:

[...] na experiência, procura ocasiões para complicar o conceito, para aplicá-lo, apesar da resistência desse conceito, para realizar as condições de aplicação que a realidade não reúne. É então que se percebe que a ciência constrói seus objetos, que nunca ela os encontra prontos. A fenomenotécnica prolonga a fenomenologia. Um conceito torna-se científico na proporção em que se torna técnico, em que está acompanhado de uma técnica de realização (BACHELARD, 2005, p. 77, grifos do autor).

Ocorre o mesmo na psicanálise: tomando o conceito de Inconsciente como exemplo, sua delimitação conceitual enquanto fenômeno só foi possível a partir do momento a técnica psicanalítica foi criada. Nas palavras de Freud (1996[1940], p. 226), a psicanálise depende de "métodos técnicos" para "[...] preencher as lacunas existentes nos fenômenos de nossa consciência". Foi dessa maneira que se tornou possível o conhecimento de processos que seriam incognoscíveis não fosse o fato de virem acompanhados de uma 'técnica de realização' específica. Malgrado a posição tomada e defendida pelo inventor da psicanálise, restam alguns argumentos a respeito das possibilidades de verificação dos fenômenos psicanalíticos e de sua inclusão no rol dos fatos científicos.

\section{A PESQuisa EMPírica e O PROBlema da VERIFICAÇÃo EM PSICANÁlise}

Internamente ao próprio campo psicanalítico, existem algumas correntes mais significativas de pensamento a respeito do problema da pesquisa em psicanálise como, por exemplo, a anglo-americana que, inscrita em uma tradição empirista da ciência, busca formas de quantificar a produção de conhecimento da psicanálise. Aqui, Kernberg (2006) é um dos principais porta-vozes dessa vertente pois, com efeito, sugere mudanças na forma como a investigação em psicanálise é realizada. Para ele, seria absolutamente necessário um incremento na quantidade de análises cientificas a respeito dos resultados e da eficácia do que ele chama de "psicoterapia psicanalítica". O objetivo desta intensificação seria avançar no conhecimento e reassegurar o público a respeito dos efeitos benéficos e do escopo da psicanálise, além de fortalecer seu lugar entre as ciências. A falta de esforços na comunidade psicanalítica em desenvolver dados empíricos sistematicamente sobre sua eficácia teria resultado na abertura de espaço para terapias cognitivo-comportamentais, as quais realizam pesquisas empíricas constantes sobre suas modalidades de tratamento.

A pesquisa aqui é entendida como observações sistemáticas sob condições controladas que possam levar a novos conhecimentos (KERNBERG, 2006, p. 920). Para Kernberg (2006, p. 923), a pesquisa empírica deve considerar as questões conceituais envolvidas no estudo, para não correr o risco de chegar a resulta- 
dos de medida equivocados que não corresponderiam aos conceitos investigados. Por outro lado, a pesquisa conceitual - debruçada sobre o desenvolvimento histórico, as controvérsias e o uso predominante de certos conceitos - pode revelar-se estéril se não for baseada em evidências empíricas (KERNBERG, 2006). Daí sua insistência na necessidade da adoção do método clínico vinculado a uma investigação experimental através do estabelecimento de relações entre a pesquisa clínica psicanalítica e a observação de mudanças de comportamento dos pacientes (KERNBERG, 2006, p. 921). Para terem "pertinência científica", as questões teóricas e clínicas devem ser relacionadas aos achados empíricos.

Nesse mesmo artigo, Kernberg reconhece as dificuldades metodológicas na condução dessas pesquisas, dada a impossibilidade de uma aproximação empírica capturar os processos inconscientes envolvidos no decorrer de um atendimento. No entanto, Kernberg (2006) enfatiza que, apesar das críticas à negligência quanto à natureza do processo terapêutico nas pesquisas quantitativas, seria relevante para o estudo empírico das psicoterapias psicanalíticas relacionar a observação de comportamentos à investigação clínica. Mas, seria a investigação clínica um meio legítimo de coleta e análise de dados empíricos pertinentes, já que estes estão unicamente vinculados a um comportamento observável? Não fica claro quais critérios definiriam esses comportamentos, nem por quem eles devem ser observados para possuírem "pertinência cientifica". Segundo o autor,

[...] a cristalização de formulações conceituais contrastantes, juntamente com potenciais observações sistemáticas disponíveis para se distinguir as diferentes consequências de seus empregos respectivos constitui um primeiro passo na direção da pesquisa empírica (KERNBERG, 2006, p. 924).

Apesar de reconhecer que o desenvolvimento e a evolução da psicanálise se deram através do trabalho de teóricos e clínicos, Kernberg (2006, p. 925) defende que o efeito cumulativo de pesquisas bem direcionadas se moveria na direção de uma melhora da psicoterapia. Em longo prazo, a integração proposta entre pesquisa conceitual, clínica e empírica contribuiria significativamente para a evolução da psicanálise, além de possibilitar o aumento de suas aplicações e intensificar o contato com outros (neuro)cientistas.

Além disso, o autor enfatiza também a necessidade de vínculos entre psicanálise e academia em departamentos de universidades, bem como o recrutamento e a inclusão, nas sociedades psicanalíticas, de cientistas com sólida formação em pesquisa empírica. Tal posicionamento é defendido por outros autores de renome internacional, além de Kernberg, tais como Wallerstein (1986), Clarkin, (CLARKIN; YEOMANS; KERNBERG, 1999). A preocupação com a falta de verificação empírica que, segundo autores, ameaçam a psicanálise, levou à criação, nos EUA, de uma Sociedade para o Avanço da Pesquisa Quantitativa (SAQRP) em 1989 (LO BIANCO, 2003). O intuito desses profissionais é, portanto, o de fazer com que a psicanálise se atualize constantemente e possa se encaixar e se alinhar mais estreitamente com o conhecimento que a ciência verificada empiricamente permite. 


\section{O LUGAR da ClíniCA NA PESQUiSA: A ESPECIFICIDAdE DO OBJETO}

Ainda outra defesa da legitimidade científica da psicanálise parte da idéia de que, ao invés de se insistir em uma perspectiva empírica e quantitativa, devese investir na valorização da produção de um sistema coerente e consistente de conceitos teóricos e de uma técnica de investigação apropriada que seja desenvolvida tendo em vista o objeto da psicanálise - o Inconsciente. Ou seja, uma posição mais próxima àquela de Freud e de Bachelard. O que está em pauta aqui são as "[...] questões de rigor e da precisão das conceituações teóricas quase sempre deixando entrever a especificidade do objeto da psicanálise" (LO BIANCO, 2003, p. 117). Ursula Dreher (2002) sustenta que nem sempre é possível para a ciência utilizar-se do método experimental, como por exemplo, na Arqueologia e na Astronomia, dentre outras. De modo que o progresso científico deve contar, não apenas com dados empíricos, mas também com o desenvolvimento de conceitos, como é o caso do conceito de seleção natural elaborado por Darwin (DREHER, 2002, p. 19) e considerado um dos pilares da Biologia.

A pesquisa em psicanálise tem seu principal ponto de apoio na clínica espaço no qual tratamento e pesquisa ocorrem simultaneamente. Tanto na pesquisa conceitual quanto na clínica espera-se a emergência de novos conteúdos que seriam, por sua vez, articulados a uma teoria. A situação analítica poderia funcionar, ainda, como mediadora que estruturaria os dados surgidos, preparando-os para uma interpretação orientada por uma teoria de referência e dando origem a um novo conhecimento (LO BIANCO, 2003). Enquanto algumas outras ciências aplicam uma metodologia para investigar um objeto aparentemente delimitado a priori, o objeto psicanalítico se atualizaria entre o discurso de cada indivíduo e a escuta do analista na clínica, na relação transferencial. Vê-se como a pesquisa é dependente da transferência e da associação-livre, que permitem a emergência do Inconsciente: o momento da constituição do objeto é o mesmo do estabelecimento do modo de pesquisá-lo. Método, teoria e pesquisa são, assim, interdependentes e operam simultaneamente na clínica, constituindo, na realidade, uma coisa só: a prática psicanalítica. Essa organização peculiar das condições de possibilidade de construção do conhecimento psicanalítico, ao contrário de outras ciências, não tem a opção de produzir novos dados sem revelar a si mesma.

Daí a pesquisa em psicanálise estar fortemente em contato com a clínica e com a singularidade de cada caso. E mais: o psicanalista encontra-se implicado no material que surge em cada sessão, não sendo apenas uma variável a ser controlada. Por isso a necessidade de que a escuta seja específica e técnica para que os juízos do psicanalista sejam minimamente influenciados por seus valores pessoais, suas aversões, seus preconceitos e suas próprias questões pessoais. Além disso, há o trabalho do psicanalista sobre as questões que surgem na relação com o paciente e que exigem a formulação de hipóteses teóricas claras e precisas. É em um “[...] movimento constante de ida e vinda da teoria para a realidade surgida na clínica [que] irão delimitando-se, circunscrevendo-se os conceitos que, articulados, aperfeiçoarão a teoria" (LO BIANCO, 2003, p. 120). Entendida como um conjunto de idéias abstratas cuja aplicação ao material bruto da observação lhe confere inteli- 
gibilidade, a teoria é uma forma de sistematizar os dados observados. O próprio Freud expõe claramente sua perspectiva a esse respeito em sua conhecida definição da psicanálise apresentada em um verbete enciclopédico. Segundo esse texto, a psicanálise seria: (1) um procedimento de investigação dos processos anímicos de difícil acesso por outras vias; (2) um método de tratamento fundado nessa investigação e (3) um corpo teórico decorrente deste procedimento, o qual paulatinamente se configurou como uma nova disciplina cientifica (FREUD, 2007[1923]).

Considerando-se a particularidade do objeto de estudo introduzido pela psicanálise, a saber, os processos inconscientes e o aparato psíquico, percebe-se que não poderia se tratar de torná-lo apreensível pelas técnicas e métodos de investigação de outras áreas de saber. O conceito de Inconsciente operou como um corte epistemológico ou uma ruptura paradigmática com as outras ciências, ou seja, deu início a um movimento fundador de uma nova ciência. Dito de outro modo, o que esse novo objeto revelou foi a necessidade de outro entendimento da pesquisa e do conhecimento igualmente legítimos em termos de cientificidade. A noção de paradigma e o critério de cientificidade (a reunião de uma comunidade cientifica em torno de dado paradigma) propostos por Kuhn (2006) ajudam a esclarecer o argumento.

Para Kuhn (2006), uma ciência madura seria aquela que sustenta uma tradição científica normal - ou seja, uma sucessão de tradições na qual cada uma possui sua própria teoria e seus próprios métodos de pesquisa - e guia a comunidade científica por um certo tempo até ser abandonada e substituída. No entanto, para que tal estado de coisas seja alcançado, é necessário que um "paradigma" sólido esteja em vigência, legitimando e orientando uma prática científica. Kuhn (2006), logo no prefácio do seu Estrutura das Revoluções Científicas, considera os paradigmas como "[...] as realizações científicas universalmente reconhecidas que, durante algum tempo, fornecem problemas e soluções modelares para uma comunidade de praticantes de uma ciência" (KUHN, 2006, p. 13). O consenso dos cientistas em torno de um paradigma seria, assim, pré-condição para que se afirmar que um campo de estudo tornou-se, de fato, uma ciência. Ocorre que, de tempos em tempos, o paradigma vigente de uma dada ciência torna-se incapaz de explicar determinados fenômenos designados como "anomalias". Quando a quantidade dessas anomalias se torna muito numerosa e começa a ameaçar a unidade do paradigma sobre o qual a ciência se desenvolve, acontece uma crise da qual surgirá um novo modelo paradigmático, um novo enfoque da realidade, capaz de abarcar e dar conta daqueles eventos que anteriormente eram inexplicáveis.

Historicamente, então, pode-se arriscar a afirmação de que foi em um momento de crise paradigmática, no qual as doenças mentais (principalmente a histerias) evidenciavam diversas "anomalias" no paradigma vigente, que a psicanálise propôs outro recorte sobre os fenômenos e estabeleceu um novo paradigma, possibilitando soluções que antes não eram possíveis. Em termos kuhnianos, poderia-se afirmar que ela fez com que toda uma comunidade cientifica se formasse em torno desse novo paradigma e desse origem a diversas pesquisas com base em uma idéia comum a todos, a saber, a da existência de processos psíquicos 
inconscientes. Como consequência, surgiram novas compreensões a respeito dos processos psíquicos, assim como novas formas de intervenção clínica, possibilitando o desenvolvimento e a evolução de uma nova disciplina.

\section{Psicanálise: Subversão da CiênCia?}

O argumento acima baseia-se na idéia de que a psicanálise é uma ciência exatamente por apresentar um objeto de estudo definido e uma técnica de pesquisa que dá origem a uma teoria coerente e sólida. Contudo, no texto "A Ciência e a Verdade", Jacques Lacan (1988[1965]) defende outro ponto de vista e inaugura outra linhagem de abordagem do problema. Ele reconhece que a psicanálise nasceu da ciência, porém, entende que a primeira introduziria na segunda algo novo que assume um valor de uma subversão. A questão da cientificidade da psicanálise é tratada a partir do raciocínio de que "[...] a psicanálise introduziu na ciência aquilo mesmo que, tendo-o inventado e sendo por ele sustentado, a ciência exclui: o sujeito" (ELIA, 1999, p. 43, grifo do autor). Para Miller (2002), a psicanálise não poderia ser considerada uma ciência justamente por situar o sujeito no cerne de seu discurso, ao passo que as ciências, por sua vez, teriam referentes externos no centro de seu interesse. Como explica Elia (1999, p. 45), “[...] a ciência é um discurso constituído pela invenção de um sujeito, o sujeito cartesiano, que, no entanto, deve ser extraído de seu campo para que ela opere". O sujeito da ciência e o sujeito do inconsciente - objeto da psicanálise - seriam, portanto, o mesmo e sua equivalência resultaria da compreensão da ciência segundo a qual esta teria surgido, em sentido estrito, com a física-matemática numa tentativa de tratar o real pelo simbólico (MILLER, 2002). Nota-se com clareza a influência dos trabalhos de Koyré na leitura lacaniana, pois o primeiro concentra seus estudos sobre Galileu e seu modo de fazer ciência, dizendo que o florentino teria criado a ciência moderna ao tratar a Natureza pela Geometria Euclidiana (KOYRÉ, 1991).

Enquanto Galileu teria tornado possível a "[...] disjunção do simbólico e do imaginário, do significante e da imagem" (MILLER, 2002, p. 45), Descartes teria elaborado o sujeito da ciência através do cogito. Por que Descartes afirma "penso, logo sou", após ter efetuado todo um esvaziamento subjetivo pelo exercício da dúvida, Lacan (1985[1964]) compreende que esse sujeito cartesiano só é sede da identidade e do eu no instante em que pensa. Nas palavras de Lacan (1985[1964], p. 39): "Descartes nos diz - 'Estou seguro, porque duvido, de que penso', e - diria eu, para me manter numa fórmula não mais prudente que a sua, mas que nos evita debater o 'eu penso'- 'Por pensar, eu sou'". Como acontece com frequência, Miller (2002, p. 51) explica:

[...] é um sujeito que, em seu ponto de emergência, não é de nenhum modo uma substância, e sim, pelo contrário, um sujeito completamente dessubstanciado. [...] Esse sujeito, que rompeu com todas suas aderências naturais, com toda significação que não seja o resíduo pontual e desvanecente onde o pensamento e o ser formam um; esse sujeito é 
estruturalmente o agente do discurso da ciência. E esse sujeito que, em seguida põe em ação um significante em sua relação com outros significantes [...].

Assim, sujeito da ciência, sujeito do significante e sujeito do inconsciente se equivalem, já que o primeiro põe em ação o segundo e o sujeito do inconsciente é o sujeito do significante (KAUFMANN, 1996).

Como conseqüência, a psicanálise, ao invés de fazer parte da ciência, a subverteria, por permitir a emergência de um discurso diferente daquele da ciência ao não foracluir o sujeito. Apesar de ambas partirem do mesmo real, a ciência excluiria o sujeito, enquanto a psicanálise buscaria escutar os efeitos desse real nele. Dessa forma, ela estaria localizada como um ponto inapreensível no seio do discurso científico. Em resumo, mesmo sendo derivada da ciência, a psicanálise realizaria um furo naquela por ter como objeto o sujeito, exatamente uma parte que deve ser excluída da ciência para que ela possa funcionar. Nas palavras de Luciano Elia (1999, p. 50, grifos do autor):

Ao excluir de seu campo o sujeito, a ciência precisamente não o inclui como real, como impossível a dizer, como aquilo que não cessa de não se escrever, incluído, no entanto, em seu seio, como um furo no simbólico que constitui seu discurso. Incluir o real como impossível não é a mesma coisa que excluí-lo, foracluí-lo de seu campo, porque, neste último caso, podemos dizer que, em algum lugar, esse real assim foracluído persevera consistindo.

Vale lembrar que o discurso lacaniano versa a partir de um registro diferente daquele de onde fala Freud e as outras posições apresentadas acima. Enquanto o campo de Freud e dos outros autores citados é científico-técnico, os argumentos de Lacan definem-se por um desvio, uma mudança desse campo para outra área, o "registro antropológico-ético" (STENGERS, 1990) e, consequentemente, a psicanálise estaria situada "[...] em um âmbito bastante resistente à captação conceitual da ciência" (MILLER, 2002, p. 47). Ela seria um lugar de resistência às práticas tecno-científicas já que, para Lacan (1988[1965]), tratar-se-ia do sujeito da psicanálise e não da técnica psicanalítica. Tal deslocamento operado pelo discurso lacaniano permite que ele emita julgamentos de valor sobre a produção científica, pois, se o sujeito do inconsciente é o sujeito da ciência, a psicanálise estaria um passo "além" da ciência. Por considerar o sujeito e dar-lhe uma escuta, o discurso psicanalítico situaria o saber (inconsciente) no lugar da verdade. O discurso científico, por sua vez, produziria apenas um saber consciente desarticulado da verdade do sujeito. Logo, ao se situar em oposição à ciência, ao incluir o sujeito, a psicanálise teria condições de apontar a falha da primeira, a saber, sua insuficiência quanto à verdade. 


\section{Conclusão}

Ao propor um breve debate sobre o tema da cientificidade da psicanálise, expondo diferentes argumentos tanto a favor quanto contra um pertencimento desta ao campo da Ciência, pretendemos, não uma defesa de um ou outro posicionamento, mas mostrar que as possibilidades de resposta à questão são inteiramente dependentes do quê se considera como Ciência. Percebe-se que importa menos uma definição (ou não) do estatuto cientifico da disciplina psicanalítica do que a explicitação das bases sobre as quais cada autor - ou grupo de autores - constrói sua argumentação. Pois, dependendo de onde se estabelece a fronteira entre o que é cientifico e o que não o é, o estatuto da psicanálise necessariamente muda.

Independente da conclusão à qual se chegue, não há como estabelecer uma hierarquia entre as diversas ciências, uma vez que os métodos de uma não podem ser impostos à outra. As condições de possibilidade de existência de cada disciplina, seus conceitos, seus pressupostos e instrumentos são adequados àquele campo definido, sendo inaptos para aplicações em outras áreas de conhecimento (WINOGRAD, 2004). No entanto, o ponto fundamental, como nos lembra Mezan (2007, p. 354), é que a garantia da validade de qualquer conhecimento cientifico recai sobre a aplicação de métodos obrigatoriamente não-arbitrários. Para que o progresso de qualquer ciência se dê, seja ela definida como for, é absolutamente necessário que haja um núcleo sólido de informações coerentes. Uma teoria só será aceita se apresentar consistência interna, compatibilidade com os princípios gerais do campo epistemológico a que pertence e capacidade para lidar com novas descobertas, podendo ser modificada quando desafiada por algum novo fenômeno que a desafie com sucesso. O modelo psicanalítico cumpre todas essas exigências, seja em termos de coerência teórica e sua relação com o método de investigação forjado por ele, seja quanto as mudanças ocorridas na teoria e na técnica em decorrência de eventos que pusessem a psicanálise à prova. Ainda que os critérios e os argumentos aqui apresentados sobre a cientificidade da psicanálise sejam diferentes e mantenham em aberto a discussão, nenhum deles põe em questão a qualidade ou pertinência da teoria freudiana dentro dos contextos explicitados e esclarecidos por Freud ao longo do desenvolvimento de sua criação. 
Nathalia Sisson; Monah Winograd

\section{REFERÊNCIAS}

ASSOUN, P. L. Introdução à Epistemologia Freudiana. Rio de Janeiro: Imago, 1983.

BACHELARD, G. Atualidade da história das ciências. In: CARRILHO, M. M. (Org.). Epistemologia: Posições e Críticas. Lisboa: Fundação Calouste Gulbekian, 1991.

BACHELARD, G. A formação do espírito cientifico. Rio de Janeiro: Contraponto, 2005.

CLARKIN, J. F.; YEOMANS, F. E.; KERNBERG, O. F. Psychotherapy for borderline personality. New York: Wiley, 1999.

DILTHEY, W. Introduction a las Ciéncias del Espiritu (1883). México: Fondo de Cultura Económica, 1949.

DREHER, A. U. Foundations for Conceptual Research in Psychoanalysis. London: Karnac, 2002.

ELIA, L. Uma ciência sem coração. Revista Ágora: Estudos em Teoria Psicanalítica, Rio de Janeiro: v. 2, n. 1, p. 41-53, jan./jun. 1999.

FAVERET, B. Neurociências e Psicanálise: há possibilidade de articulação? Revista Psicologia Clínica, Rio de Janeiro, v. 18, n. 1, p. 15-26, jan./jun. 2006.

FREUD, S. Projeto para uma psicologia cientifica (1895). In: . Obras psicológicas completas de Sigmund Freud. Rio de Janeiro: Imago, 1996. Edição Standard Brasileira, v. 1, p. 381-517.

FREUD, S. À guisa de introdução ao narcisismo (1914). In: . Escritos sobre a psicologia do inconsciente. Rio de Janeiro: Imago, 2004. p. 95-132.

FREUD, S. Pulsões e destinos da pulsão (1915). In: Escritos sobre a psicologia do inconsciente. Rio de Janeiro: Imago, 2004. p. 133-174.

FREUD, S. Dos artículos de enciclopédia: 'Psicoanálisis' y 'Teoría de la libido'(1923). Obras Completas de Sigmund Freud. Buenos Aires: Amorrortu, 2007. v. 18 , p. 227-254.

FREUD, S. As resistências à psicanálise(1925). In: . Edição standard brasileira das obras psicológicas completas de Sigmund Freud. Rio de Janeiro: Imago, 1996.v. 19, p. 263-279. 
FREUD, S. Explicações, aplicações e orientações (1933). In: . Edição standard brasileira das obras psicológicas completas de Sigmund Freud. Rio de Janeiro: Imago, 1996a. v. 22, p. 167-191.

FREUD, S. A questão de uma Weltanschauung (1933). In: Edição standard brasileira das obras psicológicas completas de Sigmund Freud. Rio de Janeiro: Imago, 1996b. v. 22, p. 193-220.

FREUD, S. Esboço de psicanálise (1940). In: . Edição standard brasileira das obras psicológicas completas de Sigmund Freud. Rio de Janeiro: Imago, 1996. v. 23, p. 168-247.

GRAEFF, F.G. Neurociência e Psiquiatria. In: . Revista Psicologia Clínica, Rio de Janeiro, v. 18, n. 1, p. 27-34, jan./jun. 2006.

JAPIASSU, H. Psicanálise: Ciência ou contraciência? Rio de Janeiro: Imago, 1989.

KAPLAN-SOLMS, K.; SOLMS, M. Estudos Clínicos em Neuro-Psicanálise. Rio de Janeiro: Lemos, 2005.

KAUFMANN, P. Dicionário Enciclopédico de Psicanálise: o legado de Freud a Lacan. Rio de Janeiro: J. Zahar, 1996.

KERNBERG, O. The pressing need to increase research in and on psychoanalysis. International Journal of Psychoanalysis, London, v. 87, n. 4, p. 919-923, aug. 2006.

KOYRÉ, A. Galileu e a revolução cientifica do século XVII. In: Estudos de história do pensamento cientifico. Rio de Janeiro: Forense Universitária, 1991.

KUHN, T. S. A estrutura das revoluções cientificas. São Paulo: Perspectiva, 2006.

LACAN, J. O seminário: Os quatro conceitos fundamentais da psicanálise (1964). Rio de Janeiro: J. Zahar, 1985. Livro 11.

LACAN, J. A Ciência e a Verdade (1965). In: . Escritos. Rio de Janeiro: J. Zahar, 1988.

LO BIANCO, A. C. Sobre as bases dos procedimentos investigativos em psicanálise. Psico-USF, Itatiba, v. 8, n.2, p. 115-123, jul./dez. 2003. 
MEZAN, R. "Que tipo de ciência é, afinal, a Psicanálise?" Natureza Humana, São Paulo, v. 9, n. 2, p. 319-359, jul./dez, 2007.

MILLER, J. A. Elementos de epistemologia. In: Percurso de Lacan: uma introdução. Rio de Janeiro: J. Zahar, 2002.

POPPER, K. A demarcação entre ciência e metafísica. In: CARRILHO, M. M. (Org.). Epistemologia: Posições e Críticas. Lisboa: Fundação Calouste Gulbekian, 1991.

PRUDENTE, R.; RIBEIRO, M. A. Psicanálise e ciência. Psicologia: ciência e profissão, Brasília, v. 25, n. 1, p. 58-69, jan./mar. 2005.

ROLIM, A.M. A Psicanálise é uma Ciência: Mas quem não se importa? Psicologia: ciência e profissão. Brasília, v. 20, n. 2, p. 8-11xx, abr./jun.. 2000.

STENGERS, I. Quem tem medo da Ciência? Ciência e poderes. São Paulo: Siciliano, 1990

WALLERSTEIN, R.S. Forty-two lives in treatment: A study of psychoanalysis and psychotherapy. New York: Guilford, 1986.

WINOGRAD, .M. "Matéria pensante - a fertilidade do encontro entre psicanálise e neurociência". Arquivos Brasileiros de Psicologia, Rio de Janeiro, v. 56, n. 1, p. 21-34, jul/ 2004.

Recebido em: julho de 2009 Aceito em: fevereiro de 2010 